\title{
La tela, del bastidor a la pantalla, pasando por los vestidos
}

\author{
The Danish Girl | Tom Hooper | 2015 \\ Sergio Campbell" \\ École Lacanienne de Psychanalyse
}

Recibido: 13 de junio 2016; aprobado: 12 de julio 2016

\begin{abstract}
Resumen
El deseo, cuestión central y constitutiva del psicoanálisis, es el protagonista del filme La chica danesa (Hooper, 2015) más allá de que se trate de una biopic. Y aquí, el protagonista, se muestra a veces inhibido, a veces sutil, a veces desbordado. La virtud del filme radica en no pretender explicarlo, comprenderlo ni aclararlo; mantiene al deseo en su justo lugar, su lugar de opacidad que produce el permanente malentendido y da consistencia a la observación de Lacan de que no hay relación sexual.
\end{abstract}

Palabras Clave: deseo| no relación sexual | goce

The fabric of the frame, to the screen, through dresses

Abstract

Desire, the main and constituent issue of psychoanalysis, is the protagonist of the film "The Danish Girl", in spite of the fact that it is a "biopic". And here, the desire, is sometimes seen inhibited, sometimes subtle,sometimes excessive. The virtue of the film is not to aim to explain it, understand or clarify it. It keeps the desire in its right place, its opaque place which causes permanent misunderstanding and gives place to Lacan 's observation, which says there is no sexual relationship.

Keywords: desire | no sexual relationship | enjoyment

Cosecharás tu siembra. Gálatas 6:7-10

No siempre se cumple el viejo adagio y es lo que le pasó al film La chica danesa (Hooper, 2015). Con cuatro nominaciones, sólo consiguió un premio, el de mejor actriz de reparto; lo que nos lleva a la pregunta ¿Quién es la chica danesa, Lili Elbe o Gerda Gotlieb (conocida como Gerda Weneger)?

La pregunta es retórica, pues sabemos que se trata de Lili, de la transformación de Eignar Mogens Wegener en Lili Elbe. Pero si bien es retórica, la pregunta nos permite situarnos en un lugar de interrogación sobre lo que vemos, sobre lo que Hooper nos cuenta.

El film sigue la novela The danish girl (Ebershoff, 2001) que a su vez sigue al libro de Ernst Hathorn, de 1933, bajo el seudónimo de Niels Hoyer, Man into woman. La novela y la película se basan en una historia real, sin embargo, al ser ficción y no documental, construyen un relato que no tiene por qué atarse a los acontecimientos reales. La novela se convirtió en best seller, la película no logró imponerse en Hollywood. Por alguna razón, la academia no compró los guiños a ella dedicados.

Una historia simple, narrada cronológicamente, con una hermosa fotografía y actuaciones excelentes. Así, se montaron en la potencia que siempre tiene una historia real, pero lo real de la historia, aquello que no forma parte del discurso narrativo del film, retorna para agujerearlo. El punto fuerte se transforma en debilidad.

Tomaremos entonces aquello de la historia real que fue dejado afuera. Pero antes...

\section{Un poco de cronología no viene mal}

Eignar nació en 1882 y murió como Lili Elbe en 1931. Conoció a Gerda en la Escuela de arte de Copenhague y se 
casaron en 1904, cuando Eignar tenía 22 años y Gerda 19.

En 1907, Gerda recibe el premio Neuhausens, y después de viajar por Italia y Francia, se radican en París en 1912. La transformación de Eignar en Lili había comenzado. En 1913, se descubrió que la modelo de Gerda era su propio marido.

Entre 1920 y 1930, Eignar vestía regularmente como mujer, y Gerda solía presentarla como su prima Lili.

En 1930 comienzan las operaciones, que fueron cinco en total, y que terminaron con la vida de Lili.

La pregunta retórica del principio dirige nuestra mirada sobre Gerda, esa mujer maravillosa que acompañó el nacimiento de Lili de manera conmovedora; sin embargo, aquello construido como anzuelo para el consumo masivo y el paseo por la alfombra roja, da un giro y nos permite asomarnos a lo que no es contado, a lo que es dejado por fuera y que dividiremos en dos partes: lo que retorna y lo que no.

Comencemos por lo más fácil, es decir, aquello que no retorna, aquello que es dejado por fuera de la historia para que Gerda pueda constituirse en una heroína que arranca admiración y lágrimas.

En el film, puede verse a Gerda acompañando a Lili hasta el final. La historia real no fue así: Gerda la acompañó en la primera operación, que fue exitosa; luego se casó con un diplomático italiano llamado Fernando Porta, con quien se mudó a Marruecos, donde vivió hasta 1938, para regresar a Dinamarca y exponer por última vez en 1939. Murió en julio de 1940. Allí en Marruecos se enteró de la muerte de Lili, un año después de su partida.

Lo interesante de Gerda, lo realmente interesante es un dato nada menor, y es que luego de la separación de Lili, es decir, luego de perder a su modelo, ella no pudo volver a pintar. $\mathrm{Y}$ esto es lo que nos conecta con el otro aspecto, con aquello que en el film sí retorna.

Hablemos del goce de Gerda. En el film, es Gerda quien le pide que pose para el cuadro, y aparentemente fue así. De ahí en más, casi como un juego, entre ambos fabrican a Lili. Y como en todo juego, hay un objeto, el regulador, el que pone a los partenaires a jugar ocupando cada uno su lugar. Nos referimos a los vestidos y reduciendo, podríamos decir a las telas. Si hay algo para destacar de la maravillosa actuación de Eddie Redmayne, es que nos hace sentir esa adoración por las telas; permite a cada espectador casi tocarlas y compartir el placer del tacto. La tela del bastidor dio paso a la tela de los vestidos, y ese paso lo dieron juntos.

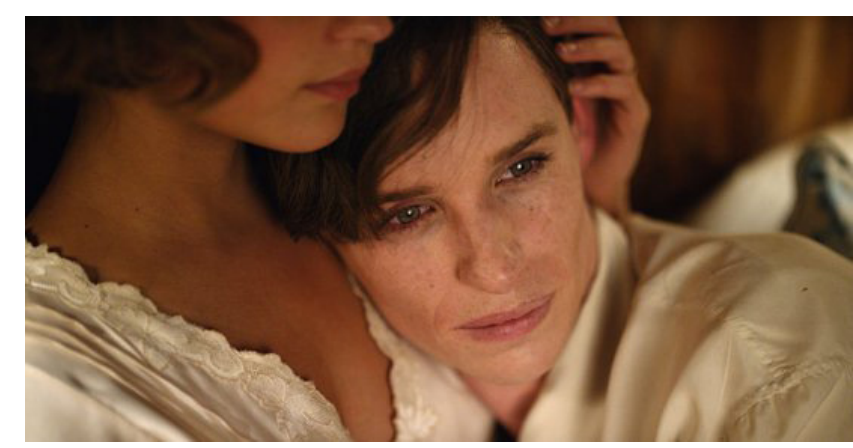

Se trata entonces de tres y no de dos, tal como ha insistido incansablemente el psicoanálisis. Se trata de un juego, de una partida diferente, porque al final, no hay un ganador, un vencedor, sino que el final marca una caída. De otra cosa no se trata la experiencia analítica; de otra cosa no se trata la relación entre Gerda y Lili.

El lugar de Gerda no es el de simple acompañamiento, como no es un simple acompañamiento el que realiza un analista en la travesía subjetiva de un analizante. Hay una fabricación donde ambos están implicados. Hay en Gerda todo un goce en juego en la parición de Lili; para utilizar esa negación tan particular a la que se entregaba Lacan, podemos decir que Lili no es sin Gerda.

Pero entonces, si ese goce compartido, mediado por las telas funcionaba, ¿Por qué se separan?

Para decirlo sumariamente: porque el deseo desencriptado de Lili iba mucho más lejos que el de Gerda, o quizás debamos decir, que Gerda.

En la medida que el deseo de Lili, habilitado por Gerda, fue encontrando su cauce, Lili no se conformó con ser travesti, ni tampoco con ser transexual; Lili quería ser mujer y mujer heterosexual, y lo que no es menor, pues podríamos decir que eso la llevó a la muerte, quería ser madre, lo que dejaba a Gerda por fuera del entramado deseante que habían construido juntos durante 26 años. Lili quería enamorarse de un hombre, y Gerda quería a Lili como su mujer. Ahí se produce el desacople, lo que no funciona, lo que pone en acto aquello en lo que Lacan insistiera -a partir de que lo enunciara por primera vez el 10 de marzo de 1969, durante su seminario De Otro al otro- que no hay relación sexual.

Mientras la tela, administrada por Gerda, sirve de velo al deseo de Lili, la cosa marcha, pero cuando se rasga el velo, cuando Lili va más allá del deseo de Gerda para encontrarse con el suyo propio, aparece el agujero tantas veces suturado, incluso a la manera de la Carta robada (Poe, 1844): la mejor manera de esconder algo es dejarlo a la vista. 
Finalmente la falla ocupa su lugar, y quizás sea el momento de hablar de las operaciones, de aquello que produce un corte y del corte, porque además nos permitirá introducir a otro personaje ausente en la historia que nos cuentan en la pantalla. Me refiero a Magnus Hirschfeld [ ${ }^{1}$.

Dijimos más arriba que Lili fue operada en cinco oportunidades, en la película se ven sólo dos y un solo médico, el doctor Kurt Warnekros [2.

Nacido en 1882, en 1925 asume como director de la Clínica para mujeres de Dresde. Esa es la clínica que aparece en la película; sin embargo, hay en la vida de Lili, otro médico y otra clínica, y que no carece de importancia por su relación con el psicoanálisis.

Magnus Hirschfeld nació en 1868. Activo defensor de los derechos homosexuales, fundó en 1897, el comité científico humanitario para luchar por la abolición del artículo 175 del código penal imperial, que pasaba a considerar a los homosexuales como delincuentes y por lo tanto podían ser encarcelados.

Colaborador de Freud, aunque con diferencias que se irían acrecentando con los años, fundó en 1908, junto a Karl Abraham, la Asociación Psicoanalítica de Berlín. Ese mismo año, de camino a Italia visitó por primera vez a Freud. En 1910, participó de la fundación de la IPA y publicó su libro Die Travestiten (1910) acuñando el término travestismo.

Freud, por su parte, lo citó profusamente en sus Tres ensayos para una teoría sexual(1905) y aunque allí se sirvió el plato que desenmascaró las diferencias, no dejaron de colaborar el uno con el otro. En 1907, Freud aportó dinero al Comité científico humanitario, y publicó en la revista de dicho comité, el artículo Relación entre las fantasías histéricas y la bisexualidad.

El interés por la bisexualidad fue lo que los acercó, y también lo que los alejó. Además de Jung, claro. En varias oportunidades, Jung se mostró contrario a la colaboración entre la Asociación y el Comité.

En 1911 se produjo la ruptura. En el Congreso de Weimar, Jung y Hirschfeld discutieron acaloradamente, y a su regreso a Berlín, este último decidió abandonar las filas del Psicoanálisis. El 29 de octubre, Abraham le comunicó a Freud la decisión de Hirchfeld, a lo que Freud, en transferencia - todavía - con Jung, no le dio ninguna importancia (Freud, 1997).

A partir de ese momento, las críticas de Hirschfeld a Freud se hacieron públicas.

En 1919, Hirschfeld fue protagonista de una situación excepcional, actuó en el considerado primer filme gay de la historia; nos referimos a Diferente a los de- más, dirigida por Richard Oswald y protagonizada por Conrad Veidt. El papel asignado a Hirschfeld es el de... él mismo.

\section{Las diferencias}

Si bien la bifurcación de caminos estuvo trazada desde un inicio, compartieron un trayecto, con la expectativa mutua de que pudieran acercarse. Hirschfeld lo dice de otro modo, compara el trabajo de psicoanalistas y sexobiólogos como el trabajo de los obreros que cavan un túnel, empezando de puntos opuestos; si mantienen la dirección correcta, se encontrarán en el medio.

Sin embargo no fue lo que ocurrió. Cuando Freud publica su ensayo sobre Leonardo, cuestiona, sin nombrarlo, la posición de Hirschfeld:

Los homosexuales han emprendido en nuestros días una enérgica campaña contra la limitación que las leyes imponen a su actividad sexual y gustan de presentarse, por boca de sus representantes teóricos, como una especie sexual diferenciada desde un principio: esto es como un grado sexual intermedio y como un tercer sexo. Según ellos, son hombres cuyas condiciones orgánicas los obligan desde su nacimiento a gustar de los hombres y repeler, en cambio, a la mujer. Aunque por razones de orden humanitario pudiéramos inclinarnos a suscribir sus peticiones, no debemos, en cambio, aceptar sus teorías, que han sido construidas sin tener en cuenta para nada la génesis psíquica de la homosexualidad. (Freud, 1910 [1973], pp. 1598).

En este pequeño párrafo pueden encontrarse sintetizadas las diferencias. Mientras Freud otorgará una importancia decisiva a la cuestión psíquica, es decir, a ese combo que constituirá la piedra angular del Psicoanálisis, el complejo de Edipo, articulado al complejo de castración, Hirschfeld profundizará en lo constitutivo, en lo biológico. De ahí lo dicho: la bisexualidad será lo que los acercará y lo que los alejará. Hirschfeld abonará la teoría de un tercer sexo, de la intersexualidad.

Retomando el filme, hay una escena que, pareciera al menos, sugerir ese trasfondo biológico de Lili. Los dolores abdominales y el sangrado de nariz. Podríamos, ya que forma parte, aunque de un modo tangencial, de esta historia, tentarnos y decir que el fantasma de Fliess [ ${ }^{3}$ y su teoría de los ciclos ligados a los corchetes de la nariz, sobrevuela la imagen.

A pesar de ello, Hirschfeld, en 1926 detallará lo que para él, serán los aportes más importantes del Psicoaná- 
lisis: la teoría sobre la represión sexual y la de los mecanismos de defensa.

En el año 1999, se estrena el filme Magnus Hirschfeld, el Einstein del sexo, Rosa von Praunheim. Allí, se cuenta su vida y puede apreciarse el funcionamiento del Instituto. El nombre del filme, está tomado del título de una entrevista que le hacen en Estados Unidos cuando va a dar un ciclo de conferencias. Ver este filme, junto con La chica danesa ayuda pensar la época en que transcurre la historia; pero también, para reflexionar en ese campo tensionado entre el psicoanálisis y la sexología.

Introducido Hirschfeld en la historia, veamos su relación con Lili.

En 1919, Hirschfeld funda en Berlín el Institut für sexualwissenschaft $\left[{ }^{4}\right.$, donde comenzará a tratar y a alojar a las minorías sexuales que, encontraron en dicho instituto, un lugar donde ser escuchados. Es decir, más que las personas, hubo un discurso que fue alojado ahí. Hacia allí fueron Lili y Gerda en 1930 para realizar la primera operación, la ablación de órganos. Esta operación resultó exitosa. El corte se produjo. Eignar había muerto, había nacido Lili, pero además el corte supuso el fin de la relación entre Gerda y Lili. Ya no había tela que las uniera.

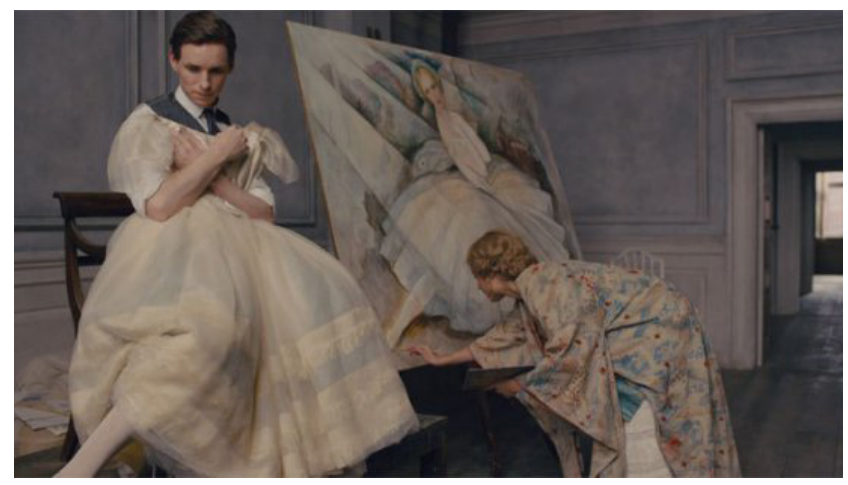

Convencido Hirschfeld de su teoría biológica, la operación no era más que una contribución a la corrección y reparación, por lo tanto, si bien la historia de Lili es presentada como la primera operación de reasignación de género, hay que decir que Hirschfeld ya había realizado esta operación a otras personas.

Por qué Lili siguió con Kurt Warnekros, es un misterio y casi una paradoja: dos años después de realizarle las operaciones, Warnekros se afilió al partido nacionalsocialista. Lo cierto es que de Berlín, Lili se dirigió a Dresde, a la Clínica que dirigía Warnekros, donde acuerdan seguir adelante, lo que significa el implante de órganos para transformar a Lili en una mujer fértil. Fueron cuatro operaciones en total. Fue un fracaso tras otro. El cuerpo de Lili rechazó los órganos trasplantados y una feroz infección la llevó a la muerte.

\section{La fragilidad de los diagnósticos}

El film ensaya diferentes tonos, incluso el paso de comedia, y es allí donde detendremos la mirada antes de finalizar. Son apenas unos minutos donde se nos muestra a Lili en un raid por diferentes especialistas, que concluye en la fuga de un psiquiátrico. En el medio, la visita a un analista: "Lamento informarle que Ud. es homosexual".

\section{¿Caricatura?}

Si bien seis palabras suenan a poco, esas pocas remiten a lo que se debatía en ese momento. Vamos a situarnos en 1920, año del famoso giro del $20\left[{ }^{5}\right.$ donde dos textos salen a luz: Lo ominoso (1919) y Más allá del principio del placer (1920). Un giro, un nuevo dualismo pulsional y el surgimiento de una nueva tópica; y sin embargo...

Ese año se realizó uno de los congresos internacionales de la IPA y el lugar elegido fue Holanda, no sin complicados movimientos internos; tal vez por eso, un médico holandés (hasta ahora nos ha sido imposible encontrar su nombre) pide su ingreso a la IPA y estalló la discusión, ¿por qué? Porque dicho médico era homosexual.

Como puede leerse en la correspondencia completa de Freud, el año 1920 se inicia con una circular firmada por él, donde aborda la cuestión. En resumidas cuentas, los vieneses, siguiendo a Freud, cuya posición respecto a la homosexualidad es bien conocida y que puede sintetizarse en que no se trataba de una patología y por ende no había nada que "curar", estaban a favor, pero los alemanes e ingleses, no. El argumento central: si un homosexual no había podido curarse de su homosexualidad en un tratamiento analítico, mal podía curar a otros; con lo cual, sólo traería descrédito al Psicoanálisis y a la Asociación.

Eso explica quizás, por qué el Instituto fundado por Hirschfeld en $1920\left[{ }^{6}\right.$, se llenaba de pacientes pertenecientes a las minorías sexuales, y los consultorios de los analistas continuaban vacíos de "perversos".

Suele justificarse que dicha discusión y la posición de algunos miembros de la IPA, están relacionadas con la época, pero precisamente, la presencia de Hirschfeld lo desmiente.

Por otra parte, es la época de una gran liberalidad en Europa; estamos hablando de la Europa de entreguerras, de la Europa que ve surgir las vanguardias artísticas, y 
de la Alemania en la que gana las elecciones el Partido demócrata social.

Entonces no se trata de un problema epocal, el problema se encuentra al interior del psicoanálisis. Si el surgimiento del psicoanálisis implicó dos renuncias: la del suceso traumático real, y la de la biología como destino (a pesar de la tan conocida frase de Freud), la entronización del complejo de Edipo como articulador de la elección sexual, llevaba a una pendiente sin salida: todo aquello que no respondiera a la normalidad edípica, implicaba un desvío, y por ende pasible de ser patologizado.

Paradójicamente, liberarse del yugo de la biología arrastró al Psicoanálisis a sumarse al discurso regulador de los placeres. Así, el discurso jurídico y el discurso médico, encontraron un aliado para el disciplinamiento sexual. Por el contrario, a Hirschfeld, la biología le ayudó a no patologizar ni la homosexualidad ni otras "desviaciones" sexuales.

Debió pasar mucho tiempo para que fronteras adentro del psicoanálisis empezara a debatirse el tema. Mucho tiempo, y todavía resuenan los ecos de una sexualidad normatizada que no se decide del todo a soltar el complejo de Edipo como estructurante de una sexualidad normal, transparente, sin opacidades.

\section{Referencias}

Freud, S. (1997). Correspondencias completas. Madrid. Biblioteca Nueva.

Freud, S. (1905 [1973]). Tres ensayos para una teoría sexual. Madrid: Biblioteca Nueva.

Freud, S. (1910 [1973]). Un recuerdo infantil de Leonardo Da Vinci. Madrid: Biblioteca Nueva.

Llorca Diaz, A. (1997). “Magnus Hirschfeld y su aportación a la ciencia sexológica” en Revista española de sexología. № 81 -82. Madrid: Publicaciones del Instituto de sexología de Madrid. (S/D).

\footnotetext{
1 Hirschfeld, Magnus, (1868-1935)

2 Warnekros, Kurt 1882-1949.
}

3 Wilhelm Fliess (1858-1928) fue un otorrinolaringólogo nacido en Polonia, que desarrolló su actividad profesional en Berlín, y con quien Freud sostuvo una relación de amistad y un intercambio epistolar en los inicios de sus investigaciones (1884-1904); proponía el estudio de correspondencias estructurales entre los órganos genitales femeninos y la nariz, o el estudio de "periodicidades" en los sujetos humanos a partir del modelo de los ritmos menstruales.

$4 \quad$ El Instituto de creado y dirigido por Hirschfeld, será saqueado y sus libros quemados luego del ascenso del nazismo.

5 El giro del 20 implica grandes modificaciones teóricas en el psicoanálisis, surgidas de la mano del fin de la primera guerra mundial. Un nuevo dualismo pulsional, "pulsiones de vida y pulsiones de muerte”, la insistencia repetitiva, que Freud llamará compulsión a la repetición, y el surgimiento de una nueva tópica, un nuevo modo de cartografiar el aparato psíquico, "ello, yo y super yo”. Ligado a estas modificaciones, surgirá la primera clínica psicoanalítica, el instituto de Berlín, fundado por Eitingon, antiguo discípulo de Freud, y el surgimiento del estatuto de formación del psicoanalista.

6 Tanto el instituto fundado por Hirschfeld como el fundado por Eitingon, se encontraban en Berlín; mientras en el primero, encontraban un lugar las minorías sexuales, en el otro eran atendidos los humillados soldados alemanes. 